\title{
INHOMOGENEOUS MULTI-PARAMETER BESOV \\ AND TRIEBEL-LIZORKIN SPACES ASSOCIATED \\ WITH DIFFERENT HOMOGENEITIES AND \\ BOUNDEDNESS OF COMPOSITION OPERATORS
}

\begin{abstract}
JIAN TAN
Abstract. In this paper, the author establishes inhomogeneous multi-parameter Besov and TriebelLizorkin spaces associated with different homogeneities. Moreover, the boundedness of the composition of two inhomogeneous Calderón-Zygmund singular integrals of order $(\varepsilon, \sigma)$ with different homogeneities is obtained.
\end{abstract}

Mathematics subject classification (2010): 42B20, 42B35.

Keywords and phrases: Besov space, Triebel-Lizorkin space, inhomogeneous Calderón's reproducing formula, different homogeneities, singular integral.

\section{REFERENCES}

[1] M. Frazier, B. JAWERTH, A discrete transform and decompositions of distribution spaces, J. Funct. Anal. 93 (1990), no. 1, 34-170.

[2] D. Goldberg, A local version of real Hardy spaces, Duke Math. J. 46 (1979), no. 1, 27-42.

[3] Y.-C. HAN, Y.-S. HAN, Boundedness of composition operators associated with different homogeneities on Lipschitz spaces, Math. Res. Lett. 23 (2016), no. 5, 1387-1403.

[4] Y.-S. HAN, C.-C. LIN, G. LU, Z. RUAN, E. SAWYER, Hardy spaces associated with different homogeneities and boundedness of composition operators, Rev. Mat. Iberoam. 29 (2013), no. 4, 1127-1157.

[5] Y.-S. HAN, S. LU, D. YANG, Inhomogeneous Besov and Triebel-Lizorkin spaces on spaces of homogeneous type, Approx. Theory Appl. (N.S.) 15 (1999), no. 3, 37-65.

[6] Y.-S. HAN, D. MüLleR AND D. YANG, A theory of Besov and Triebel-Lizorkin spaces on metric measure spaces modeled on Carnot-Carathéodory spaces, Abstr. Appl. Anal., (2008) 250 pages. Art. ID, 893409.

[7] S. Lu, Y. Ding, D. YAn, Singular integrals and related topics, World Scientific Publishing Co. Pte. Ltd., Hackensack, NJ, 2007. viii+272 pp.

[8] Y. Meyer, R. CoIfman, Wavelets: Calderón-Zygmund and Multilinear Operators, Cambridge Univ. Press, Cambridge, UK, 1997.

[9] D. Phong, E. M. STEIn, Some further classes of pseudodifferential and singular-integral operators arising in boundary value problems. I, Composition of operators. Amer. J. Math. 104 (1982), no. 1, $141-172$.

[10] H. RAUHUT, T. UlLRICH, Generalized coorbit space theory and inhomogeneous function spaces of Besov-Lizorkin-Triebel type, J. Funct. Anal. 260 (2011), no. 11, 3299-3362.

[11] E. M. STEIn, Harmonic analysis: real-variable methods, orthogonality, and oscillatory integrals, With the assistance of Timothy S. Murphy. Princeton Mathematical Series, 43. Monographs in Harmonic Analysis, III. Princeton University Press, Princeton, NJ, 1993.

[12] E. M. Stein, P. Yung, Pseudodifferential operators of mixed type adapted to distributions of $k$ planes, Math. Res. Lett. 20 (2013), no. 6, 1183-1208.

[13] J. TAN, Pointwise multipliers for inhomogeneous multi-parameter Besov and Triebel-Lizorkin spaces associated with mixed homogeneities, Trans. A. Razmadze Math. Inst. 172 (2018), no. 1, 101-114. 
[14] J. TAN, Y.-C. HAN, Inhomogeneous multi-parameter Lipschitz spaces associated with different homogeneities and their applications, Filomat. 32 (2018), no.9, 3397-3408.

[15] H. TRIEBEL, Theory of function spaces, Birkhäuser-Verlag, Basel, 1983.

[16] X. WU, Boundedness of composition of operators associated with different homogeneities on weighted Besov and Triebel-Lizorkin spaces, Proc. Indian Acad. Sci. Math. Sci. 124 (2014), no. 1, 81-92.

[17] X. Wu, Weighted Carleson measure spaces associated with different homogeneities, Canad. J. Math. 66 (2014), no. 6, 1382-1412. 